\title{
Study on Static and Dynamic Mechanical Properties of Hybrid Palm Stalk Fiber Reinforced Epoxy Composites
}

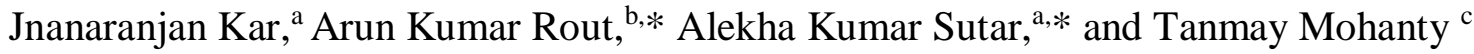

Static and dynamic effects of palm leaf stem stalk (PLSS) powder were investigated relative to the bi-directional palm stalk fiber reinforced epoxy composites. The PLSS bio-filler was incorporated into the epoxy resin by varying its content from 0 to $15 \mathrm{wt} \%$. The hybrid palm-epoxy composites were manufactured using the hand-lay-up technique followed by light compression molding. The results for the mechanical properties of the PLSS particle (15 wt\%)/palm/epoxy composites indicated an improvement in the tensile modulus, flexural modulus, and impact strength by approximately 33, 32 , and $21 \%$, respectively, when compared to the palm/epoxy composite. The dynamic mechanical analysis (DMA) of the composites showed an enhancement in the storage modulus, loss modulus and damping capacity ( $\tan \delta$ ) by approximately 75,95 , and $47 \%$, respectively, when compared to the palm/epoxy composite. The fiber-matrix interaction was studied using a Cole-Cole plot analysis. The swelling and degradation resistance of the composites was increased with filler addition.
\end{abstract}

Keywords: Palm stalk fiber; Mechanical properties; Thermo-gravimetric analysis (TGA);

Dynamic mechanical analysis (DMA)

Contact information: a: Catalysis Research lab, Department of Chemistry, Ravenshaw University, Cuttack 753001,India; b: Department of Production Engineering, VSSUT, Burla, Odisha768018, India; : School of Mechanical Engineering, KIIT Deemed to be University, Bhubaneswar, India,751024

*Corresponding authors: alekhasutar@gmail.com; arun.rout.6314@gmail.com

\section{INTRODUCTION}

Natural fibers are being increasingly considered as an environmentally friendly material in polymer matrices due to their renewable nature (Abdul Khalil et al. 2011; Liu et al. 2019). Unlike synthetic fiber, they offer problem-free disposal, and they are nontoxic and non-hazardous to the environment. Moreover, natural fiber has low cost, low density, good specific modulus, easy processing, and high aspect ratio for efficient stress transfer over synthetic fiber (Rout et al. 2001; Netravali 2007; Nunna et al. 2012; Sanjay and Yogesha 2017). They are widely used in the textile, automobile, construction, and composite manufacturing industries. However, the application of natural fiber has been limited for load-bearing applications due to its hydrophilic nature and lower thermal resistance properties (Akkus et al. 2018). The above limitations can be resolved by employing several chemical treatments of the fiber before any specific use. Chemically treated plant fiber-reinforced composites show improved mechanical and thermal resistance properties compared with the raw fiber-reinforced composites (Ray et al. 2002; Demir et al. 2006; Asumani et al. 2012; Fiore et al. 2015; Sarkar et al. 2017; Kar et al. 2018; Reddy et al. 2019).

Atiqah et al. (2017) reported that silane-treated sugar palm fiber incorporated in polyurethane composite had a positive impact on tensile and interfacial shear strength. 
Similarly, Ojha and Biswal (2019) evaluated the hardness and mechanical properties of granite filled palm-epoxy composites. They concluded that the hardness and impact strength of palm-epoxy composites increased with granite addition and a steady decline was observed in the tensile and flexural strength of the composite.

In a study of dynamic mechanical and thermal properties of jute/vinyl ester composites, the composite thermal resistance and storage modulus were improved after alkali treatment of the fiber (Ray et al. 2002). The flexural, impact, storage modulus, and loss modulus of the treated jute/epoxy are increased compared with the raw fiber (Jabbar et al. 2015). Better fiber-matrix bond strength along with improved mechanical and thermal properties of the jute/poly (lactic acid) was observed after silane and alkali treatment of jute fiber (Zafar et al. 2016). Similarly, improved mechanical, thermal, and water absorption properties of coconut and mallow-eucalyptus fiber composites were found after the chemical treatment of fiber surface (Sarkar et al. 2017; Araujo et al. 2018). Combined use of natural fiber with synthetic fiber or filler in a composite, i.e. hybrid reinforcement, can yield a positive response towards improvement in the mechanical and thermal resistance of the developed composites (Mohan et al. 1983; Nair et al. 2001; Nunna et al. 2012; Md Shah et al. 2017). Sisal/glass (Nayak and Mohanty 2010) and bamboo/glass (Samal et al. 2009) hybrid composites show enhanced thermal and mechanical properties than their individual use as reinforcement.

The dynamic mechanical analysis (DMA) is an essential and effective tool used to optimize the visco-elastic behavior of polymer composites for various engineering applications. It can be improved by incorporating various synthetic/natural fibers or fillers (micro/nano) to the polymer matrix. Combined usage of glass fiber with the sugar palm and bamboo fiber in reinforced composites improved the storage modulus, loss modulus and damping capacity of the composite (Zuhudi et al. 2016; Atiqah et al. 2018). The storage modulus and thermal resistance of oil palm-epoxy composites were improved with the addition of jute fiber into it (Jawaid et al. 2013). The visco-elastic properties of short glass fiber reinforced polypropylene composites were enhanced when calcite was added (Senturk et al. 2018). Similarly, various fillers like granite powder (Pawar et al. 2015), alumina (Patnaik and Nayak 2016), fly ash cenosphere (Satapathy and Kothapalli 2017), nano $\mathrm{ZnO}$ and $\mathrm{TiO}_{2}$ (Prasob and Sasikumar 2018), and cork (Karduman 2018) showed a positive response on the thermal behavior of composites.

In the literature, there are reports on the mechanical, dynamic mechanical analysis and thermal behavior of various plant-based fiber-reinforced composites, but there has been no such report available on DMA and thermal analysis of palm stalk-fiber reinforced epoxy composites filled with PLSS powder, though it is abundantly available. Therefore, the objective of the present investigation is to study the static and dynamic effects of palm leaf stem stalk (PLSS) powder on the bi-directional palm stalk fiber reinforced epoxy composites, and to suggest for various engineering applications.

\section{EXPERIMENTAL}

\section{Materials}

Epoxy resin LY556 (diglycidyl ether of bisphenol A) and hardener HY-951 were used as the matrix components, and they were purchased from Mohapatra Scientific Supplier, Bhubaneswar, India. The raw leaf stalks of the toddy palm (Borassus 
flabellifer) were used as the fiber, and were collected locally from Baramba village near Bhubaneswar, India. The height and age of the plant was around $50 \mathrm{~m}$ and 90 years, respectively. Baramba, Bhubaneswar is the eastern coastal plains of India and lies along the Eastern Ghats mountains. It has an average altitude of $45 \mathrm{~m}$ above the sea level.

\section{Alkali Treatment of Fibers}

Fiber treated with 5\% alkali for $6 \mathrm{~h}$ shows better mechanical property and has higher cellulose content than other durations of treatment (Rout et al. 2016). Therefore, the fibers treated with $5 \% \mathrm{NaOH}$ for $6 \mathrm{~h}$ were selected as a reinforcement material for composites. The treated fibers were cut with scissors into suitable dimensions $(200 \mathrm{~mm} \times$ $5 \mathrm{~mm} \times 0.4 \mathrm{~mm}$ ) and made into a fiber mat.

\section{Composite Fabrication}

Palm-epoxy hybrid composites were fabricated by incorporating 0 to $15 \mathrm{wt} \%$ of PLSS powder. A hand-lay-up technique was implemented for fabrication of the composite. The detailed designation and composition of the composite are shown in Table 1.

Table 1. Designation of Composite Samples

\begin{tabular}{|c|c|c|c|}
\hline \multirow{2}{*}{ Designation } & \multicolumn{3}{|c|}{ Composition } \\
\cline { 2 - 4 } & Epoxy (wt\%) & Palm fiber (wt\%) & Filler content (wt\%) \\
\hline EPP0 & 70 & 30 & 0 \\
\hline EPP5 & 65 & 30 & 5 \\
\hline EPP10 & 60 & 30 & 10 \\
\hline EPP15 & 55 & 30 & 15 \\
\hline
\end{tabular}

Initially, the PLSS dust and the epoxy resin were stirred well using a wooden stick for 10 minutes to obtain a homogenous mixture. The mixture was blended with a hardener in a ratio of $(10: 1)$ by weight before reinforcement of the fiber in the mold. A wooden mould of size $(150 \mathrm{~mm} \times 60 \mathrm{~mm} \times 5 \mathrm{~mm})$ was used. Initially, silicone gel was sprayed into the inner surface of the mould wall to facilitate easy removal of composite specimens. The mixture was then poured into the mould and the treated bi-directional fiber mat was allowed to pre-impregnate into it. Three layers of fiber mat was used (each of 1.5 to $1.8 \mathrm{~mm}$ thick) for specimen preparation. For removal of entrapped air in between the layers, a roller was used. Finally, the composite material was pressed with a load of around $30 \mathrm{~kg}$ at room temperature and was removed from the wooden mould after $24 \mathrm{~h}$. 


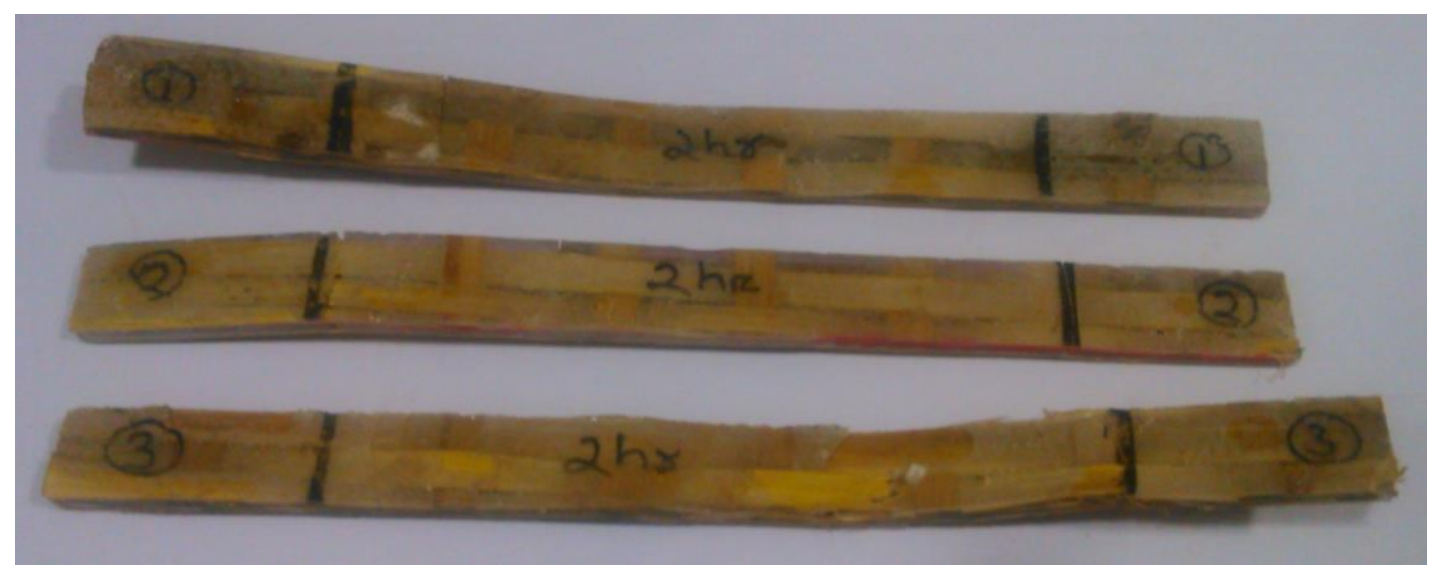

Fig. 1. Samples prepared for mechanical characterization

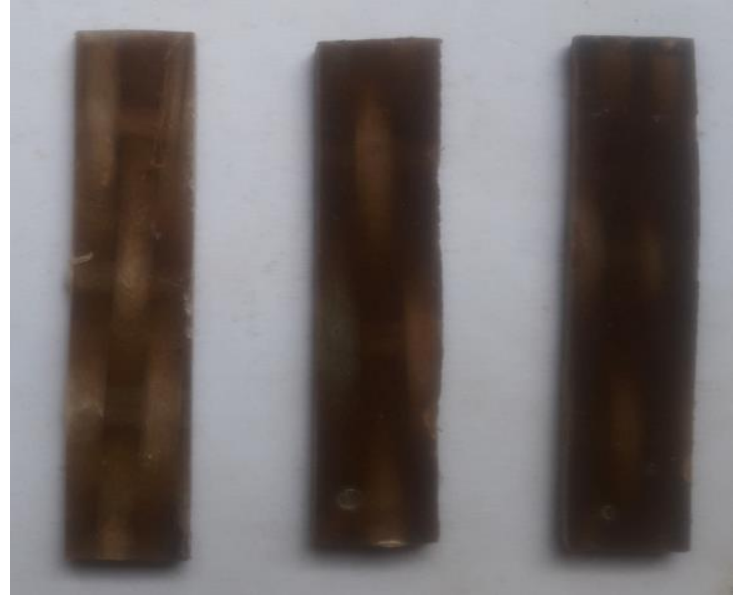

Fig. 2. Samples prepared for dynamic mechanical analysis

The material was then post-cured at ambient conditions for another $12 \mathrm{~h}$. Specimens of different sizes were then prepared using a diamond tipped cutter for mechanical and thermal characterizations as shown in Figs. 1 and 2.

\section{Methods}

Tensile test

The tensile strength of the palm-epoxy composite filled with 0 to $15 \mathrm{wt} \%$ bio filler was measured using an universal testing machine (Instron 3369; Instron India Pvt. Ltd., Chennai, India) with a gauge length of $50 \mathrm{~mm}$ and at a crosshead speed of 2 $\mathrm{mm} / \mathrm{min}$ and relative humidity of $51 \%$. The experiment was conducted as per ASTM D3039M-14 (2014) standard. Each sample $(150 \mathrm{~mm} \times 25 \mathrm{~mm} \times 4 \mathrm{~mm})$ was tested five times, and the average of the replicates was taken as the sample's tensile value.

\section{Flexural test}

The flexural strength (FS) of the hybrid palm-epoxy composite was measured using the Instron 3369 universal testing machine. The test specimens were prepared following the ASTM D790-03 (2003) standard, with the dimensions of $100 \mathrm{~mm} \times 15 \mathrm{~mm}$ $\times 4 \mathrm{~mm}$. The test was conducted with a humidity of $51 \%$. The flexural strength (FS) of the composite was calculated as, 


$$
\mathrm{FS}=\frac{3 P L}{2 b t^{2}}
$$

where, $P, b, t$, and $L$ are the maximum load $(\mathrm{N})$, the width $(\mathrm{mm})$, the thickness $(\mathrm{mm})$, and the span length $(\mathrm{mm})$ of the test sample, respectively.

\section{Impact test}

The impact strength of the composite specimens with dimensions of $(66 \mathrm{~mm} \times 13$ $\mathrm{mm} \times 4 \mathrm{~mm}$ ) was measured using an IZOD impact tester (Veekay Test Lab, Mumbai, Maharashtra, India) as per ASTM D256-10 (2010) standard. The testing samples were mounted into the impact testing machine and the energy absorbed during each test was calculated. Each specimen was tested five times, and the average of these values was taken as the impact strength value. The test was conducted with a humidity of $51 \%$.

Dynamic mechanical analysis (DMA)

The DMA of palm-epoxy composite with and without filler content was performed in a three-point bending mode on Tritec 2000 DMA device (Triton Technology Ltd., Nottinghamshire, UK). The test specimens $(13 \mathrm{~mm} \times 56 \mathrm{~mm} \times 3 \mathrm{~mm})$ are prepared as per the ASTM D256-08 (2008) standard. The test was carried out at the atmospheric condition in a temperature range of 25 to $150{ }^{\circ} \mathrm{C}$ with a heating rate of $10{ }^{\circ} \mathrm{C}$ per minute and a fixed frequency of $1 \mathrm{~Hz}$. The storage modulus $\left(E^{\prime}\right)$, loss modulus $\left(E^{\prime /}\right)$, and $\tan \delta$ of the specimens were observed during the run.

Thermogravimetric analysis (TGA)

The thermal behavior of palm stalk fiber and the PLSS dust reinforced palmepoxy composites were studied as per the ASTM E1131-08 (2008) standard. The test was performed on STA7200 supplied by High-tech-Science Corporation (Hitachi, High-Tech Science Corporation, Tokyo, Japan). The experiment was conducted under a nitrogen atmosphere in a temperature range of 30 to $600{ }^{\circ} \mathrm{C}$ and a heating rate of $10{ }^{\circ} \mathrm{C}$ per minute.

\section{Degradation testing}

Composite specimens were prepared according to ASTM B117-03 (2003) with dimensions of $(12 \mathrm{~mm} \times 10 \mathrm{~mm} \times 3 \mathrm{~mm})$. Initially, the edges of the composite specimens were sealed with epoxy matrix, and their initial weight was measured in dry conditions. The test was then conducted by keeping the samples in $10 \mathrm{wt} \% \mathrm{NaCl}$ solution for 24,48 , and $72 \mathrm{~h}$ at a temperature of $45{ }^{\circ} \mathrm{C}$. Each specimen was rinsed with distilled water, dried in an oven at $100{ }^{\circ} \mathrm{C}$ for $15 \mathrm{~h}$, and final weights were taken.

\section{Swelling properties}

Swelling properties of PLSS filled and unfilled palm-epoxy composites were evaluated using water, methyl ethyl ketone (MEK), and dichloroethylene $\left(\mathrm{CH}_{2} \mathrm{Cl}_{2}\right)$ at room temperature. The specimens $(3 \mathrm{~mm} \times 4 \mathrm{~mm} \times 5 \mathrm{~mm}$ ) were kept inside each liquid for 15 days. The samples were then washed with tap water and dried under vacuum at $110{ }^{\circ} \mathrm{C}$ for three days. The swelling index is calculated as follows,

$$
\text { Swelling index }=1+\frac{\left(W_{\mathrm{sw}}-W_{\mathrm{d}}\right) \times \rho_{\mathrm{sp}}}{W_{\mathrm{d}} \times \rho_{\mathrm{s}}}
$$


where $W_{s w}$ is the weight of the specimen in the swollen state, $W_{d}$ is the weight of the dry specimen, $\rho_{s}$ is the density of solvent, and $\rho_{s p}$ is the density of the specimen.

\section{Scanning electron microscopy}

The surface morphology of the eroded specimens was observed using a scanning electron microscope (SEM) model JEOL JSM-6480 LV (JEOL Ltd. Tokyo, Japan).

\section{RESULTS AND DISCUSSION}

\section{Thermo-gravimetric Analysis (TGA) of Fiber}

The thermal resistance of raw and $5 \% \mathrm{NaOH}$ palm stalk fiber treated for $6 \mathrm{~h}$ is shown in Fig. 3. Thermal decomposition occurred in three steps. The initial weight loss was observed between 100 to $150{ }^{\circ} \mathrm{C}$, indicating the presence of moisture content and other volatile compounds (Kumar et al. 2018; Umashankaran and Gopalakrishnan 2020). For raw fiber, the first stage of weight loss was observed at $110^{\circ} \mathrm{C}$, while for treated fiber it was observed at $140{ }^{\circ} \mathrm{C}$. The second stage of weight loss was noticed between 290 to $350{ }^{\circ} \mathrm{C}$ for raw fiber, while the same was observed between 300 to $380{ }^{\circ} \mathrm{C}$ for the treated fiber. The second stage of deterioration indicates the removal of hemicelluloses and cellulose in the palm fiber (Reddy and Rahim 2018). The third stage of weight loss for raw fiber was observed between 350 to $410{ }^{\circ} \mathrm{C}$ and for treated fiber; it is between 380 to $450{ }^{\circ} \mathrm{C}$. The third stage of weight loss denotes the decomposition of lignin, oil contents and waxes present on the palm fiber surface (Manimaran et al. 2018; Umashankaran and Gopalakrishnan 2020).

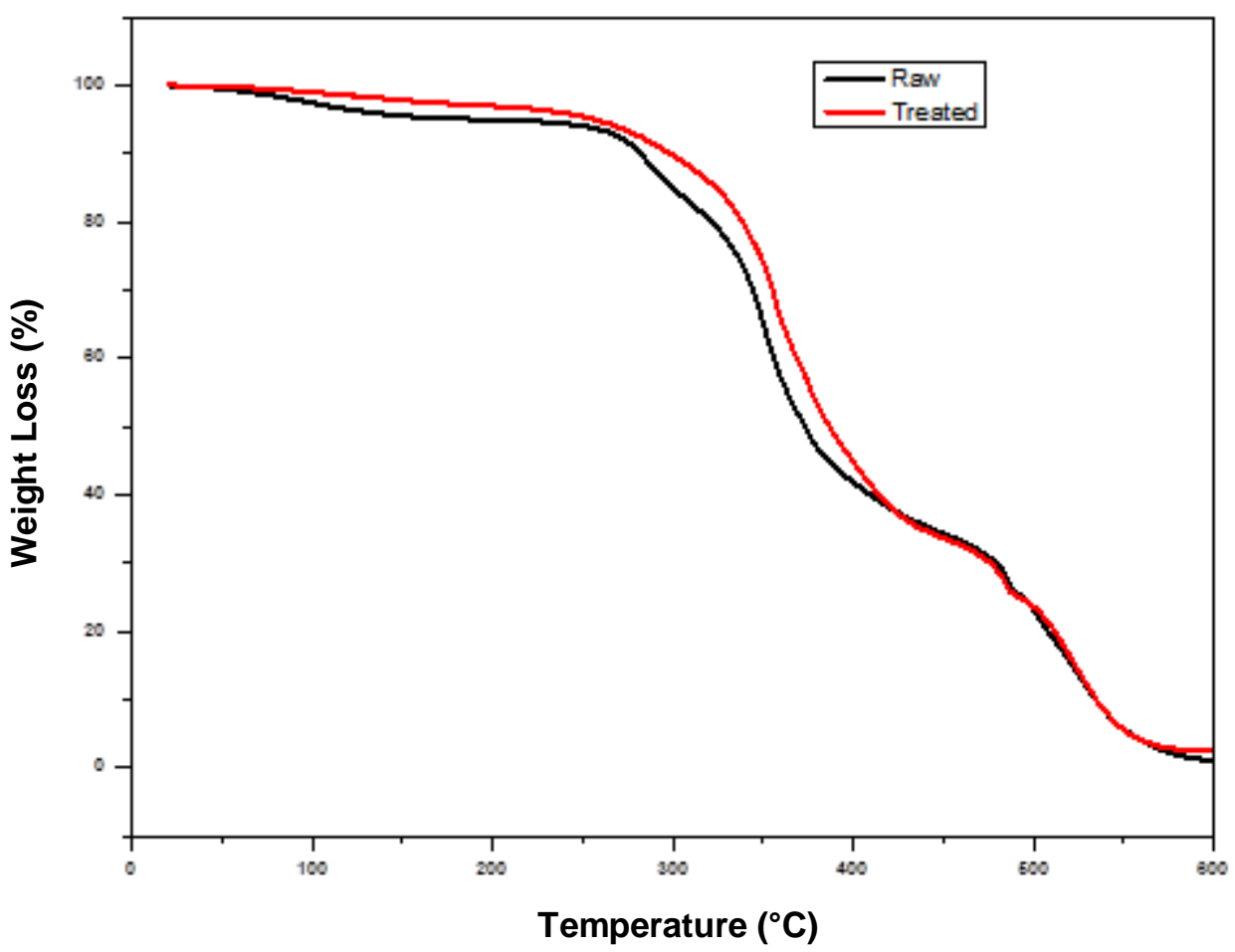

Fig. 3. TGA curve of treated and raw palm stalk fiber 


\section{Mechanical Properties of the Composite}

Tensile strength and modulus

The tensile strength and modulus values with standard deviations of the palmepoxy composites reinforced with different levels of PLSS dust (0 to $15 \mathrm{wt} \%$ ) are presented in Table 2 and shown in Fig. 4 The tensile strength gradually decreased as the filler powder level increased. The composite without PLSS had the tensile strength of 58.1 MPa, and this value dropped to $40.3 \mathrm{MPa}$, and $37.4 \mathrm{MPa}$ as the filler content was increased. This observation may be due to the poor adhesion between the epoxy matrix and the filler particles, which promoted micro-cracks at the interfaces during application of load (Fig. 5). The other reason for the reduced tensile strength was the non-uniform stress transfer from the matrix to the fibers due to agglomeration PLSS dust within the epoxy matrix. The present results are consistent with previous investigators (Srivastava and Pawar 2006) for fly-ash filled glass fiber reinforced epoxy composite and (Ojha and Biswal 2019) for granite powder-filled palm-epoxy composites.

Modulus of elasticity is the measure of stiffness or rigidity of the material, and in practice, it can be improved with filler addition. Normally, the reinforced fibers/fillers restrain the deformation of the matrix in a fiber-reinforced composite. Therefore, it is expected the increase of modulus even if the tensile strength reduces with filler addition (Rout and Satapathy 2012). In the present study, the tensile modulus of the palm-epoxy composite is increased from 2.51 GPa to $3.32 \mathrm{GPa}$ with filler addition up to $15 \mathrm{wt} \%$.

Table 2. Mechanical Properties of Hybrid Palm-epoxy Composites

\begin{tabular}{|c|c|c|c|c|c|}
\hline $\begin{array}{c}\text { Wt\% of } \\
\text { PLSS }\end{array}$ & $\begin{array}{c}\text { Tensile } \\
\text { Strength } \\
\text { (MPa) } \\
\text { [S.D.] }\end{array}$ & $\begin{array}{c}\text { Tensile } \\
\text { Modulus } \\
\text { (GPa) } \\
\text { [S.D.] }\end{array}$ & $\begin{array}{c}\text { Flexural } \\
\text { Strength } \\
\text { (MPa) } \\
\text { [S.D.] }\end{array}$ & $\begin{array}{c}\text { Flexural } \\
\text { Modulus } \\
\text { (GPa) } \\
\text { [S.D.] }\end{array}$ & $\begin{array}{c}\text { Impact Energy } \\
\text { (J) } \\
\text { [S.D.] }\end{array}$ \\
\hline 0 & $58.12[0.32]$ & $2.51[0.25]$ & $53.52[1.56]$ & $2.45[0.35]$ & $0.48[0.07]$ \\
\hline 5 & $42.85[0.38]$ & $2.82[0.32]$ & $40.15[1.76]$ & $2.71[0.38]$ & $0.53[0.06]$ \\
\hline 10 & $40.28[0.41]$ & $3.24[0.35]$ & $37.12[1.47]$ & $3.15[0.37]$ & $0.56[0.08]$ \\
\hline 15 & $37.42[0.44]$ & $3.32[0.38]$ & $34.52[1.61]$ & $3.23[0.40]$ & $0.58[0.09]$ \\
\hline
\end{tabular}

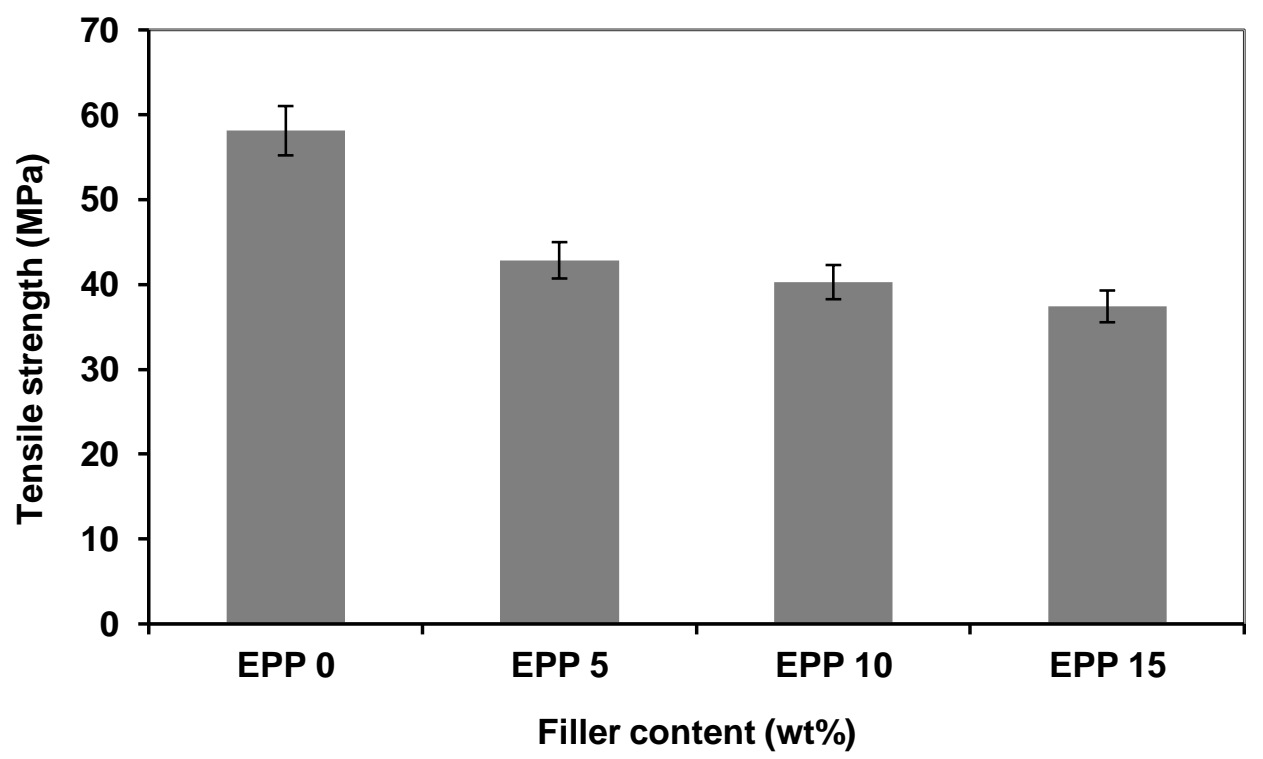

Fig. 4. Tensile strength of PLSS filled and unfilled palm-epoxy composite 


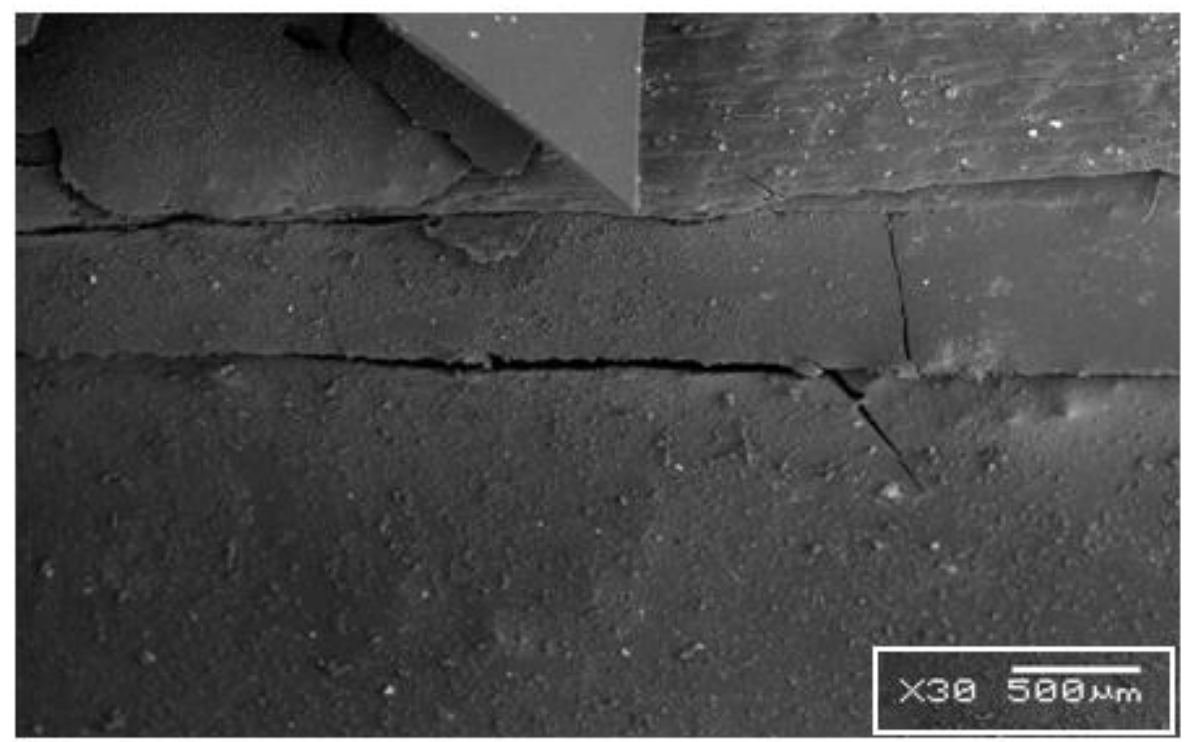

Fig. 5. SEM image of EPP15 composite showing matrix crack

\section{Flexural strength and modulus}

Flexural strength and modulus values of the palm-epoxy composites filled with ( 0 to $15 \mathrm{wt} \%$ ) PLSS filler are presented in Table 2. It can be seen that the flexural strength of the palm-epoxy composite was decreased with increasing filler concentration (Fig. 6). The bending strength of the composite sample without PLSS powder was 53.1 MPa; this value decreased to $40.2 \mathrm{MPa}, 37.1 \mathrm{MPa}$, and $34.5 \mathrm{MPa}$ with an increase in filler concentration, while an increase in the flexural modulus was observed. During the threepoint bend test, failure of the specimen occurs due to the initiation of cracks in the matrix region. The matrix crack propagates along the fiber axis, and it slowly spreads to the entire layer of the laminate, and which is known as delamination (shown in Fig. 7). However, the presence of filler particles in the matrix had restricted the crack propagation. 


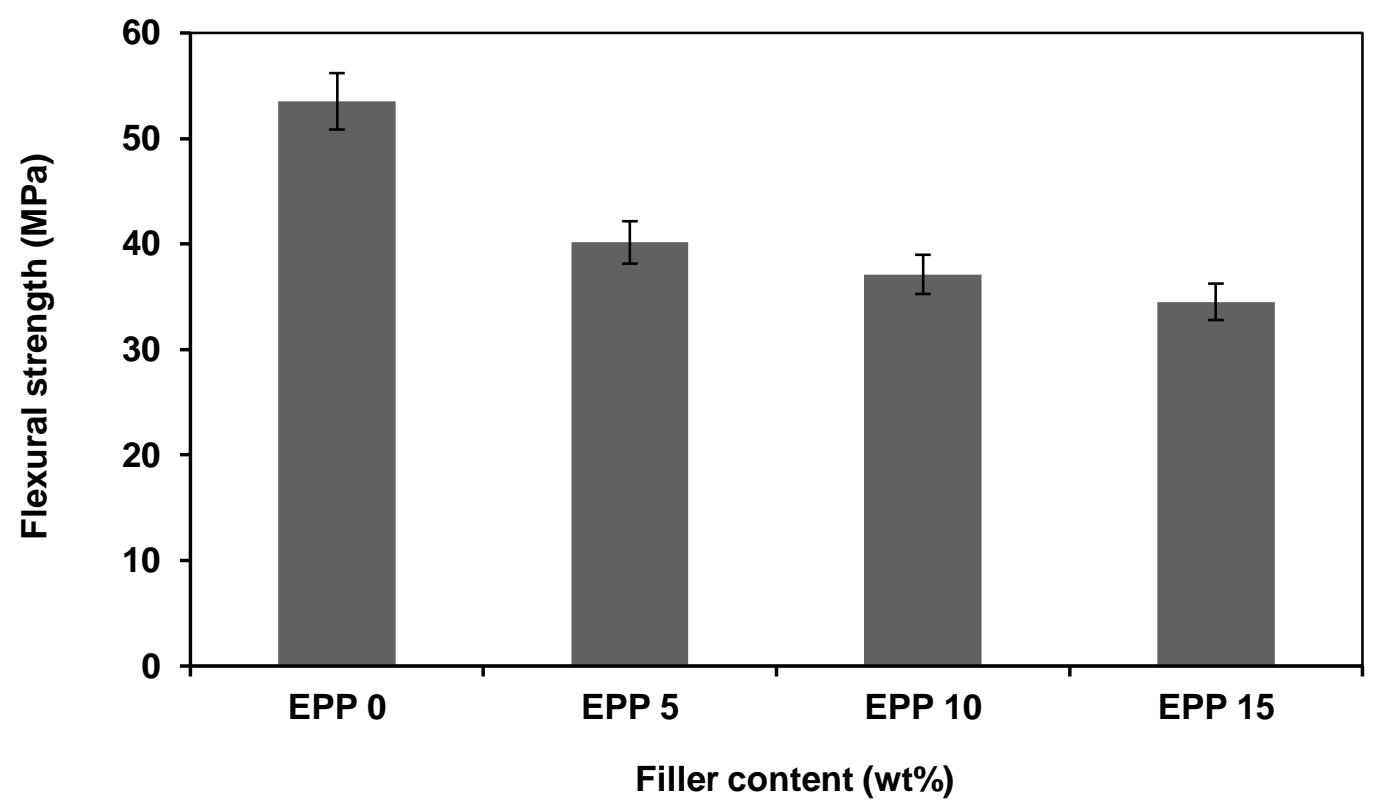

Fig. 6. Flexural strength of PLSS filled and unfilled palm-epoxy composite

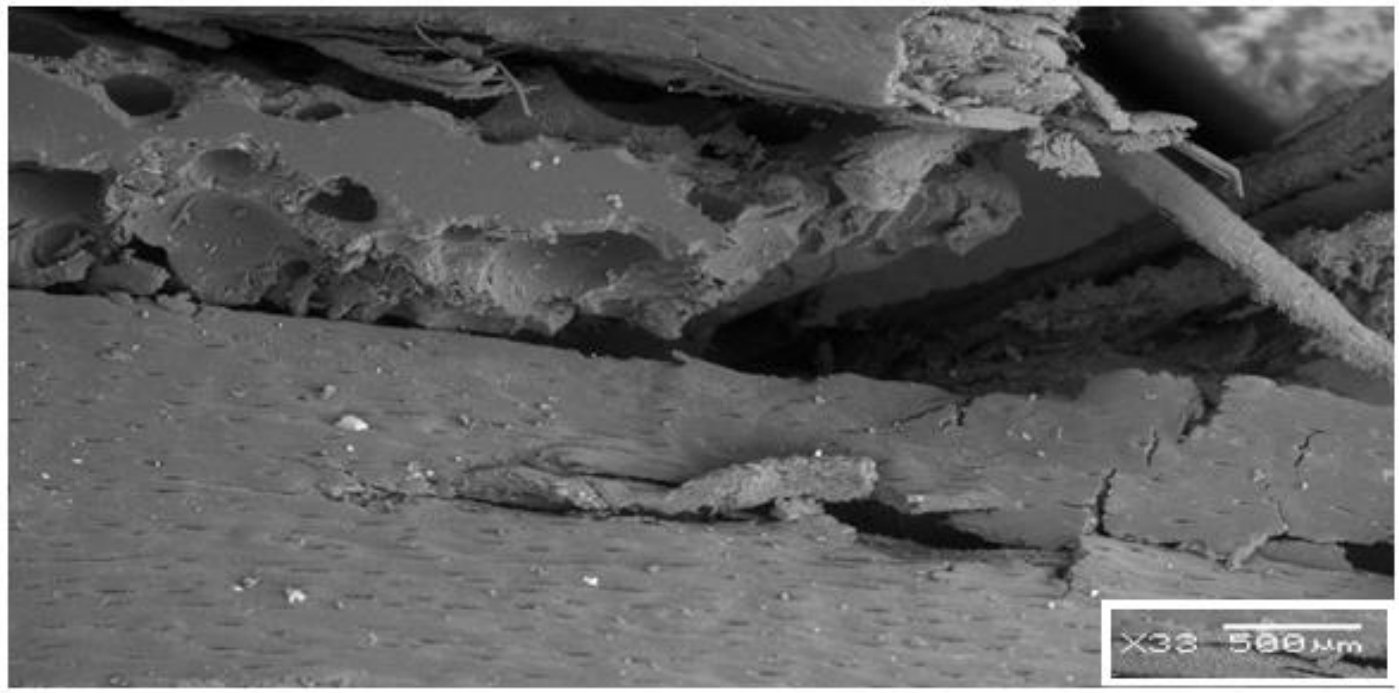

Fig. 7. SEM image of flexural fractured specimens

When the filler concentration was increased in the specimens, the agglomeration of the particles was also increased. Therefore, stress concentration zones were induced in the specimen that promoted the rapid growth of the cracks, and as a result, the flexural strength was reduced with filler addition. However, resistance to deformation of the laminate had reduced with particle addition which increased flexural modulus. Similar property modification was reported earlier by previous investigators (Ojha and Biswal 2019) for granite powder-filled palm-epoxy composites and (Biswas 2014) for copper slag filled bamboo-epoxy composites. 


\section{Impact strength}

In many engineering applications, composite specimens are subjected to impact loads. Hence, it is essential to examine the impact strength (energy absorption) of the composites. Figure 8 shows the impact energy absorption of palm-epoxy composites filled with PLSS powder.

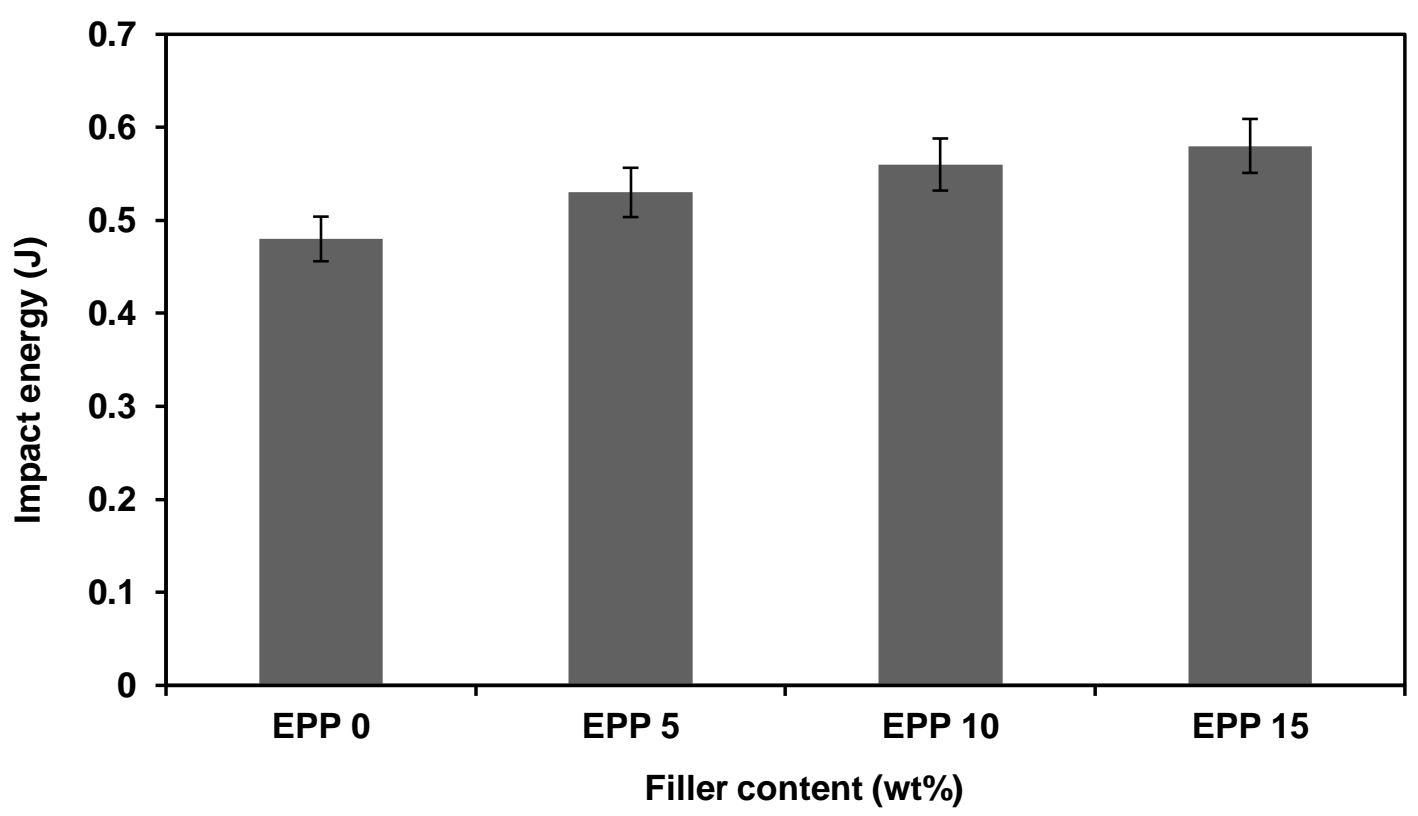

Fig. 8. Impact strength of PLSS filled and unfilled palm-epoxy composite

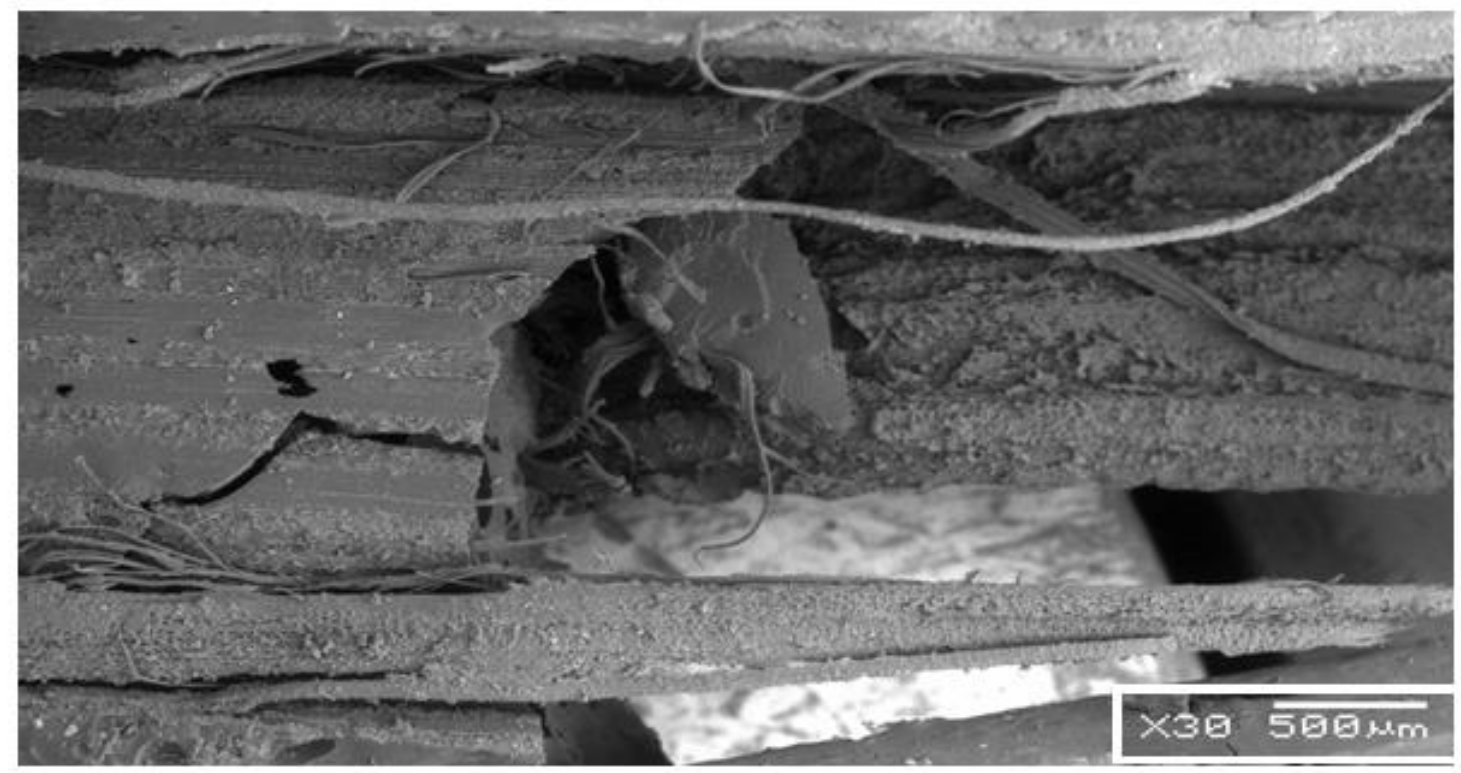

Fig. 9. SEM micrograph showing de-bonding and matrix cracks of EPP10 composites

It was found that the impact strength of the palm-epoxy composite was improved with the addition of filler. This observed behavior was due to the presence of PLSS powder at the interfacial regions, which reduced the bond strength between the palm fiber 
and the epoxy matrix. With the weaker fiber-matrix interfaces, the composite broke into many parts when subjected to impact load, which resulted in more energy being absorbed, as evidenced in the SEM micrograph shown in Fig. 9. The present results are consistent with previous investigations for cement by-pass-dust filled bamboo-epoxy composites (Gupta et al. 2012) and palm-epoxy composites filled with granite powder particulates (Ojha and Biswal 2019).

\section{Dynamic mechanical analysis (DMA)}

DMA is generally used to measure the damping capacity of composite material. When a dynamic load is applied to a composite specimen, it absorbs and releases some energy. The energy-absorbing capacity refers to the stiffness and energy dissipation capability refers to the damping capacity of the composite material. DMA measures the stiffness and damping factor by storage modulus $\left(E^{\prime}\right)$, loss modulus $\left(E^{/ /}\right)$, and $\tan \delta$.

\section{Storage Modulus ( $\left.E^{\prime}\right)$}

$E^{\prime}$ is defined as the ratio of stress that is in phase with the strain of the sinusoidal flexural deformation. The variation in storage modulus of palm-epoxy composite with filler addition is shown in Fig. 10.

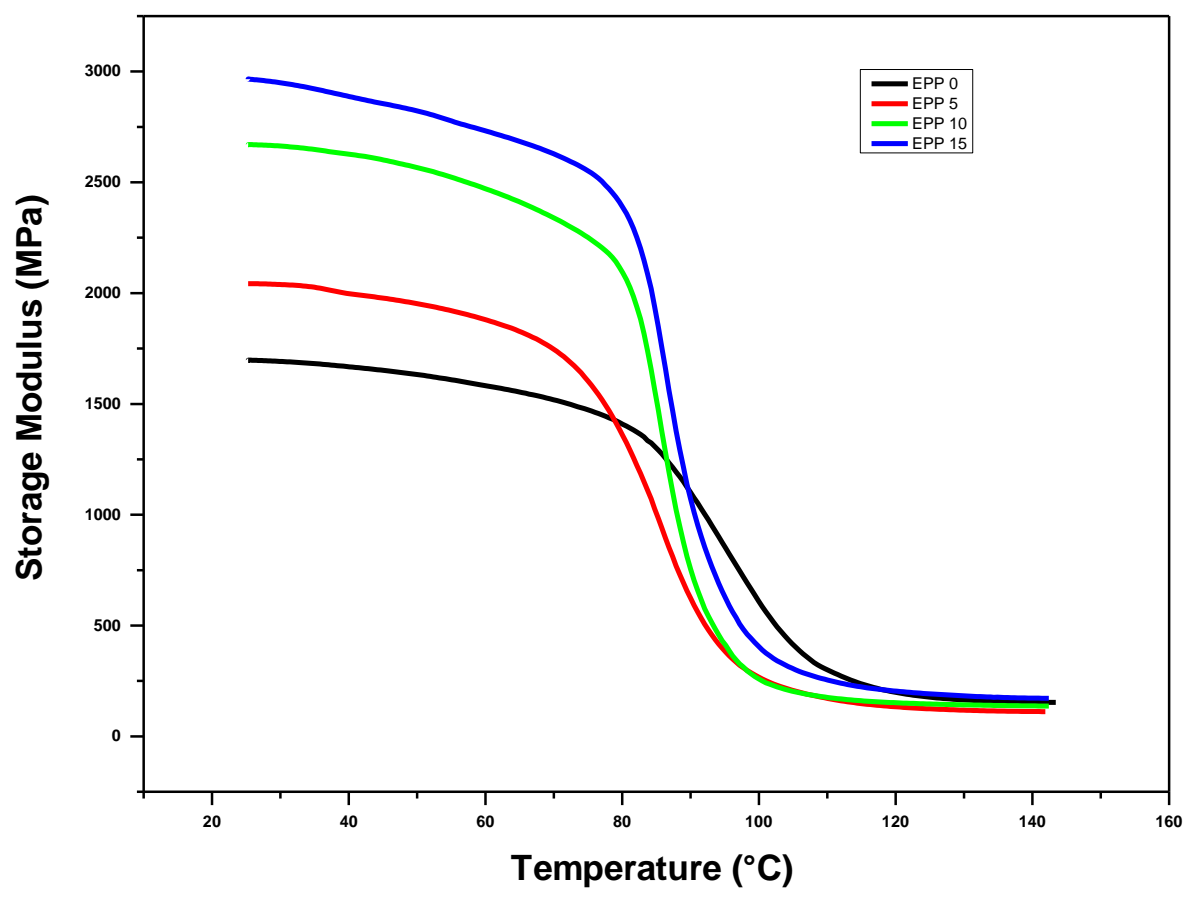

Fig. 10. The storage modulus of raw and PLSS filled palm-epoxy composites

The unfilled palm-epoxy had a storage modulus of $1694 \mathrm{MPa}$ in the glassy region, and this value increased to $2045 \mathrm{MPa}, 2690 \mathrm{MPa}$, and $2962 \mathrm{MPa}$ for $5 \mathrm{wt} \%, 10 \mathrm{wt} \%$, and $15 \mathrm{wt} \%$, respectively. This result indicated that the stiffness of the composite gradually increased to a maximum for the $15 \mathrm{wt} \%$ filled composite. Filler addition had reduced the molecular mobility and deformation of the matrix resin. However, the decrease in stiffness of all the samples with an increase in temperature was due to the molecular mobility of epoxy resin. The improvement in the stiffness of hybrid palm/epoxy 
composites demonstrated a good bonding effect of PLSS powder with the epoxy matrix. Besides, at a temperature range from $70{ }^{\circ} \mathrm{C}$ to $90{ }^{\circ} \mathrm{C}$, the hybrid composite showed a higher value of $E^{\prime}$.

Similar results were reported for kenaf-epoxy composites filled with magnesium hydroxide (Saba et al. 2019) and Adak et al. (2018) for graphene oxide filled carbonepoxy composites.

\section{Loss Modulus ( $\left.E^{\prime \prime}\right)$}

Loss modulus represents the viscous response of the material and the capacity of a material to convert mechanical energy to heat energy (Ji et al. 2011; Saba et al. 2016). It is a measure of released heat energy per cycle in a cyclic loading condition for a viscoelastic material. The conversion of mechanical energy into thermal energy per cycle is written as (Adak et al. 2018),

$$
\Delta H=\pi \varepsilon_{0}^{2}(\omega) E^{\prime \prime}
$$

where $\Delta H$ is the amount of heat energy released and $\varepsilon(\omega)$ is the strain function at the frequency $\omega$ with amplitude $\varepsilon_{0}$. Thus, the energy released of the composite under cyclic loading is directly proportional to the loss modulus. The variation of the loss modulus of the palm-epoxy composite with and without filler content as a function of temperature is shown in Fig. 11.

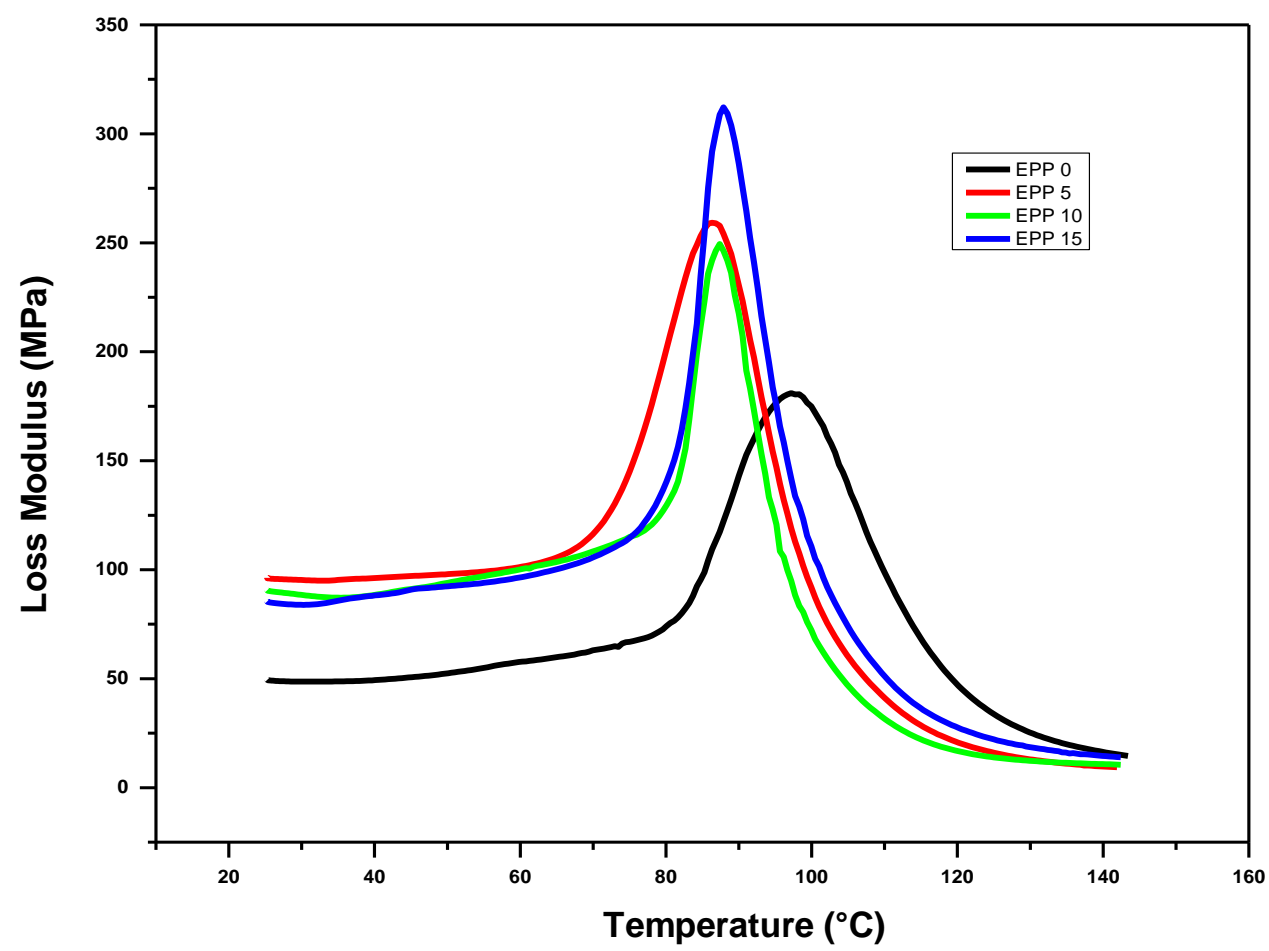

Fig. 11. The loss modulus of palm-epoxy composites with different PLSS powder

The value of $o^{\prime \prime}$ became narrow with an increase in the PLSS filler in the composite. This indicates that the addition of PLSS into the composite had restricted the polymer chain mobility. The increase in loss modulus was also attributed to the high damping capacity of the composites. 
The value of $E^{\prime /}$ initially increased, attained a maximum value in the glasstransition temperature range, and then decreased for all samples in the rubbery region. At higher temperatures (above $140{ }^{\circ} \mathrm{C}$ ), the overlapping of curves indicates that the inclusion of PLSS powder had no significant effect on the viscose dissipation (Karaduman 2018; Md Shah et al. 2019). The inclusion of PLSS improved the loss modulus of EPP0 composite from 49.6 MPa to 85.6 MPa, 90.7 MPa, and 96.3 MPa for $5 \mathrm{wt} \%, 10 \mathrm{wt} \%$, and $15 \mathrm{wt} \%$, respectively. The present results are consistent with previous research on alumina filled jute-epoxy composite (Patnaik and Nayak, 2016) and graphene oxide filled carbon-epoxy composite (Adak et al. 2018).

\section{Tan Delta}

Tan $\delta$ is expressed as a dimensionless number and represents the mechanical damping factor. It depends on fiber-matrix adhesion. Hence, a composite with weak adhesive force will have higher values of $\tan \delta$ and has a low load-bearing capacity (Martinez et al. 2007; Jawaid et al. 2013). The $\tan \delta$ values of EPP0, EPP5, EPP10, and EPP15 composites are shown in Fig. 12.

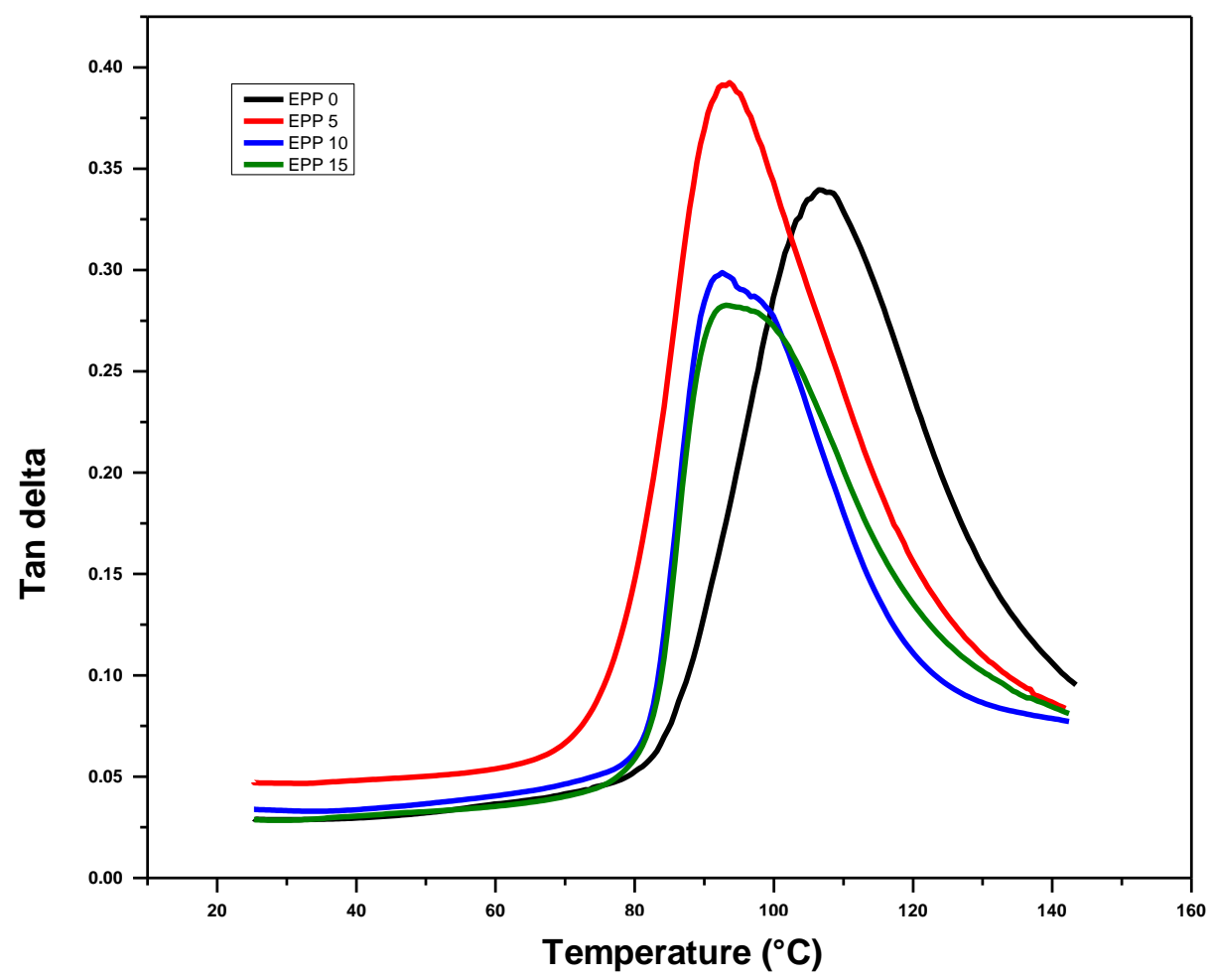

Fig. 12. Tan $\delta$ value of palm fiber reinforced epoxy composites filled with PLSS dust

It can be seen that below the $T_{\mathrm{g}}$, the damping value was low because the molecular chains were in a frozen state. In the rubbery region, the value was also found to be lower as the molecular chains are free to move due to lower resistance to flow. In the transition region, the tan delta increased as the free volume increases which increased the molecular mobility of the polymer chain. The tan delta is found to be least $(0.26)$ for pure palm-epoxy composite which shows lower molecular mobility with less energy dissipation. This behavior was due to stronger adhesive force between the fiber and the 
matrix which restricts the movement of the molecular chain. The tan delta value was increased with the addition of filler from $\left(\begin{array}{l}0 \\ 10\end{array} 15\right) \mathrm{wt} \%$ and found to be maximum $(0.38)$ for EPP15 composite showing higher dissipation of energy and more viscous behavior. This increasing tendency was attributed to the presence of more voids in the composite hence have more molecular movement showing higher damping value (De Medeiros et al. 2005; Chee et al. 2019 ; Jesuarockiam et al. 2019). Similar results were reported for jute-epoxy composite filled with granite stone powder (Pawar et al. 2015).

\section{Cole-Cole Plot}

A Cole-Cole plot is an important tool to observe the relationship between the storage and loss modulus for a visco-elastic material (Reddy et al. 2013). Further, it is generally used to study the change in composite structure at the molecular level after adding micro/nano-sized reinforcements. A Cole-Cole plot is drawn with loss modulus versus storage modulus as shown in Fig. 13.

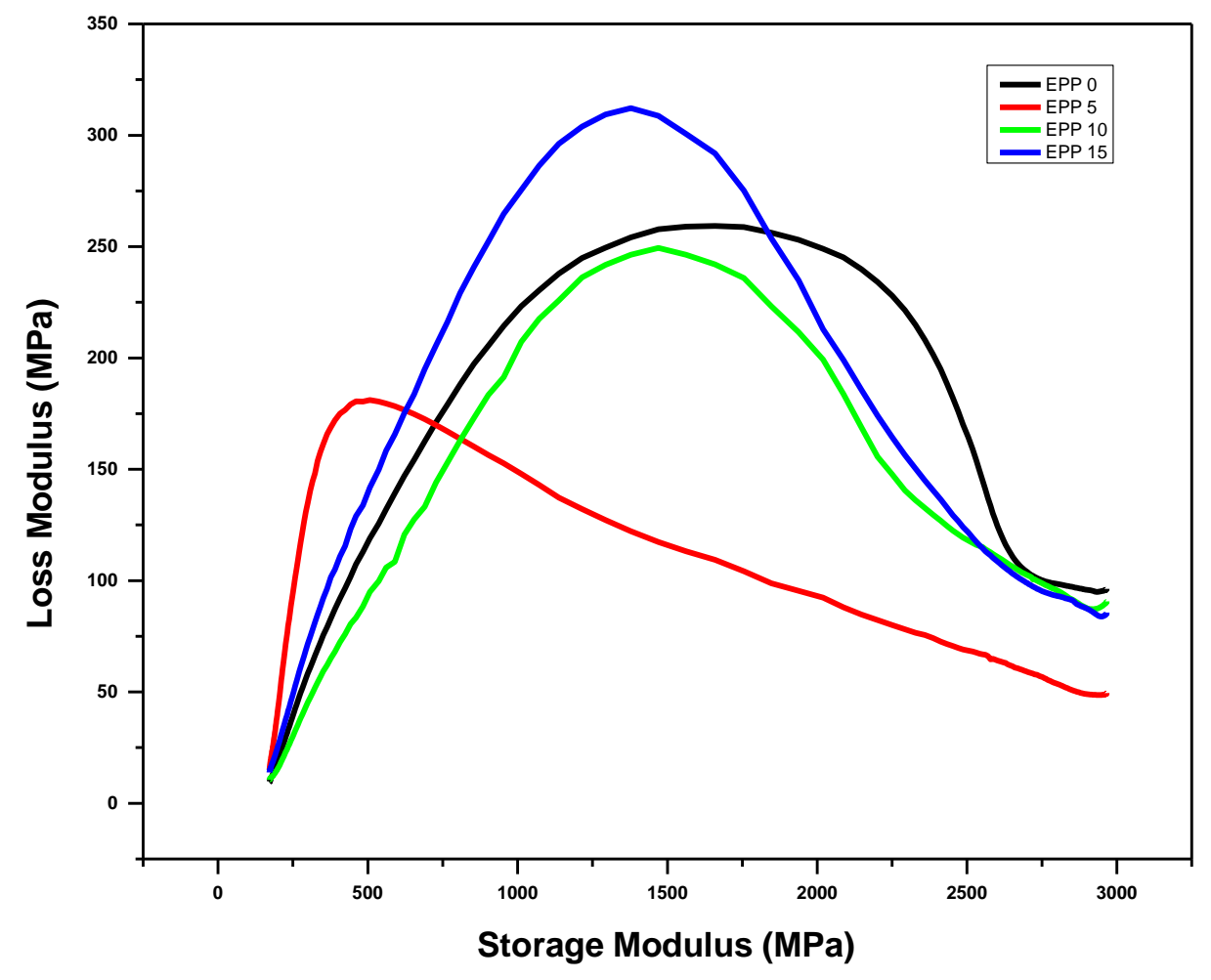

Fig. 13. Cole-Cole plot for PLSS filled and unfilled palm-epoxy composites

The homogeneous or heterogeneous nature of the composite sample could be identified from the shape of the plot (Jesuarockim et al. 2019). A perfect semicircular arc in the plot shows the homogeneous nature of the system, but an irregular/imperfect semicircular curve represents the heterogeneity of the system. Figure 13 show that the inclusion of PLSS powder increased the irregularity of the composite. The unfilled sample (EPP0) exhibited a less irregular shape compared with other samples, as expected. This behavior is attributed to the strong adhesion between the fiber and matrix. A similar 
trend was found for granite filled jute-epoxy composite (Pawar et al. 2015).

\section{Thermo-gravimetric Analysis of PLSS Filled Composites}

Thermo-gravimetric analysis was conducted for palm-epoxy composites filled with PLSS powder to observe the weight loss. Figure 14 depicts the effect of PLSS addition on the thermal stability of palm-epoxy composites. The initial degradation of all the samples occurs at 100 to $150{ }^{\circ} \mathrm{C}$ due to the vaporization of moisture content and volatile substances (Huang et al. 2018). The second stage of degradation was observed above $300{ }^{\circ} \mathrm{C}$ due to pyrolysis and decomposition of epoxy and amine hardener. The thermal degradation of palm fiber occurred in the following temperature ranges: hemicelluloses $\left(150\right.$ to $\left.350{ }^{\circ} \mathrm{C}\right)$, glycosidic linkage of cellulose $\left(275\right.$ to $500{ }^{\circ} \mathrm{C}$ ), and lignin (250 to $500{ }^{\circ} \mathrm{C}$ ) (Lomelí-Ramírez et al. 2014). Moreover, no significant difference was observed in the thermal degradation of PLSS filled and unfilled samples beyond 600 ${ }^{\circ} \mathrm{C}$. It is also observed that the addition of filler reduced the thermal resistance of the unfilled composite. The weight loss of filled samples occurred slightly earlier than unfilled ones in the temperature range of 100 to $150{ }^{\circ} \mathrm{C}$ and 300 to $400{ }^{\circ} \mathrm{C}$. Similar observations have been made for jute and kenaf epoxy composites filled with granite and magnesium powder respectively (Pawar et al. 2015; Saba et al. 2019). The decline in thermal resistance may due to the presence of voids and weak bonding between the fiber and the matrix with the addition of filler (Kar et al. 2018). With the increase of temperature, the mobility of the polymer chain increases due to the void content in the composite hence, the decomposition process became easier.

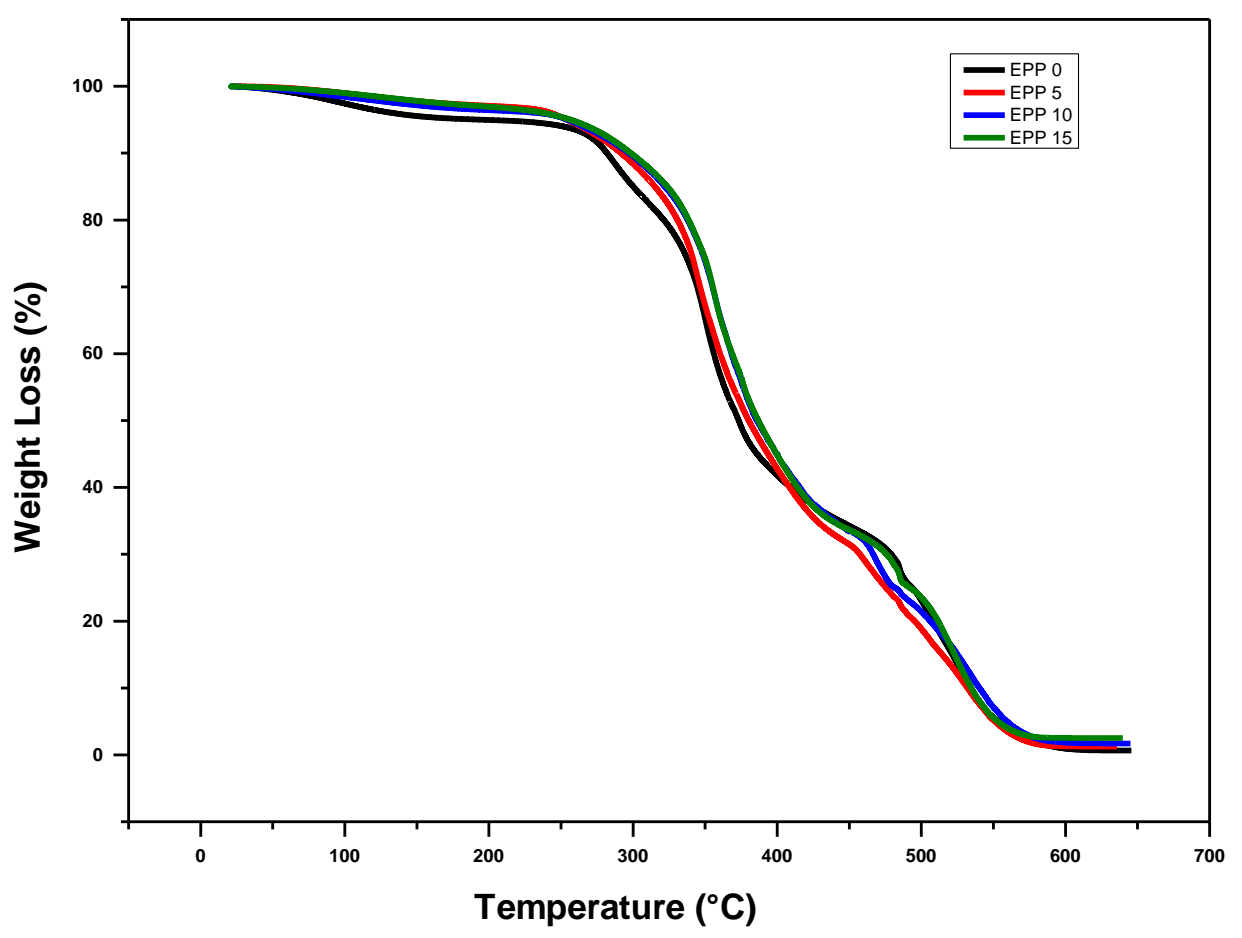

Fig. 14. Thermo-gravimetric analysis of PLSS filled and unfilled palm-epoxy composites 


\section{Degradation Properties}

The degradative tendencies of PLSS filled palm-epoxy composites are shown in Fig. 15. The weight gain of samples was small even after long hours of sodium chloride $(\mathrm{NaCl})$ treatment. Furthermore, weight gain increased with increasing filler content in the composite samples. The strong interfacial adhesion between the fiber and matrix in the unfilled samples reduced the penetration of $\mathrm{NaCl}$. Alkali treatment increased the surface roughness of the palm stalk fiber and made the interfacial bonding strong with the epoxy resin (Kar et al. 2018). However, filler reinforcement in the composite increased the void content, which led to the diffusion of $\mathrm{NaCl}$ into the matrix (Kar et al. 2018). The increase in void content may be due to weak interfacial bonding between the fiber and the matrix as a result of the clustering of filler. Hence, the weight-gain was observed for filled samples. The present result is consistent with previous reports for jute epoxy hybrid composites (Abdul Khalil et al. 2011).

\section{Swelling Properties}

The palm-epoxy composites filled with different weight proportions of PLSS powder were subjected to different solvents to evaluate the swelling index for various solvent-based applications, as shown in Fig. 16. The swelling index of unfilled samples is less than the filled ones. This obtained result may be due to stronger adhesive force between the palm fiber and epoxy matrix as a result of alkali treatment of the fiber (Kar et al. 2018). The presence of filler increases the de-bonding of the reinforcements with the matrix due to the clustering of filler (Abdul Khalil et al. 2011; Kar et al. 2018). As a result, solvents can swell the composite, and the index value increases with the increase in filler content (Law and Ishak Mohd 2010).

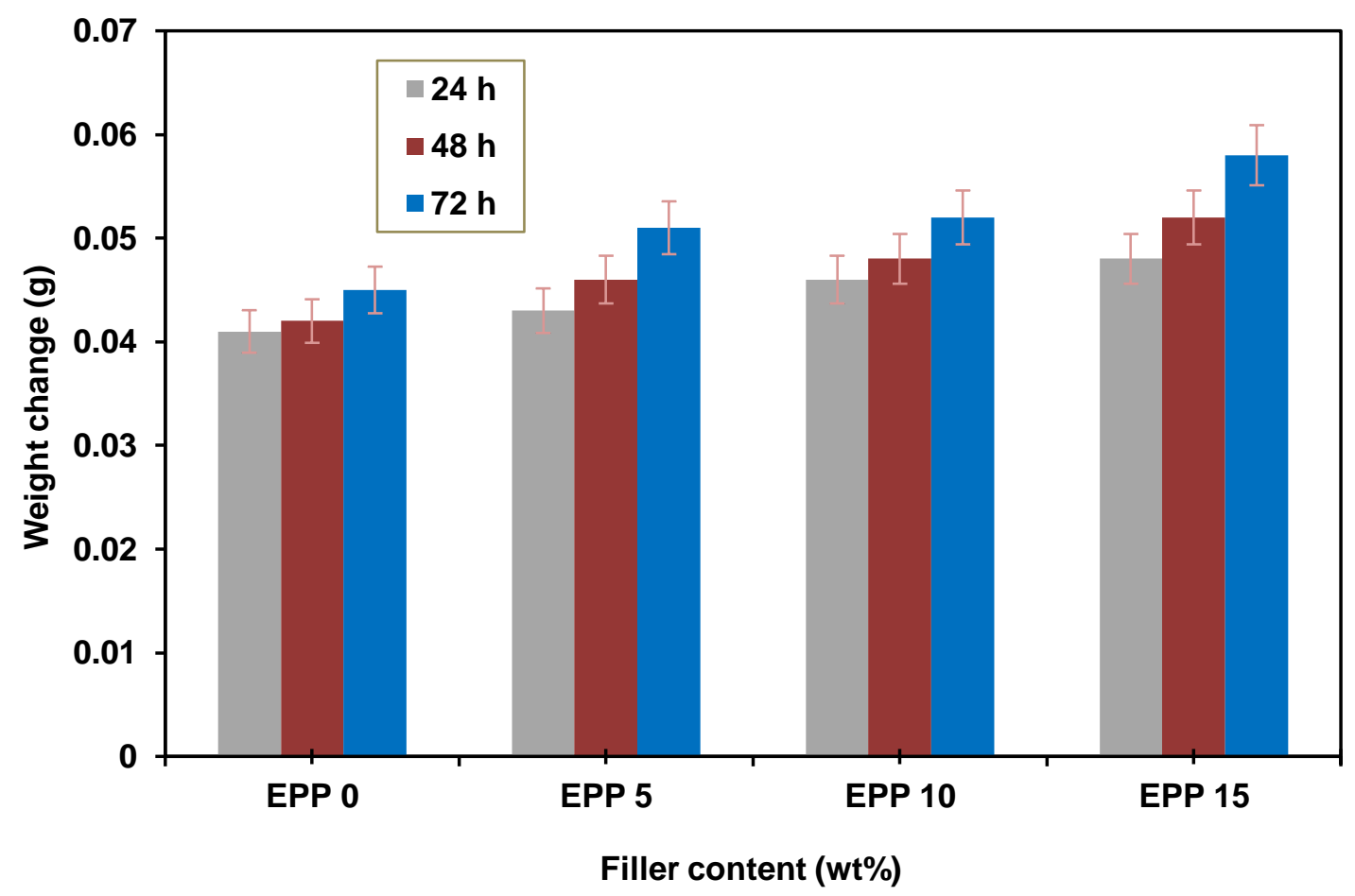

Fig. 15. Degradation properties of unfilled and PLSS filled composites 


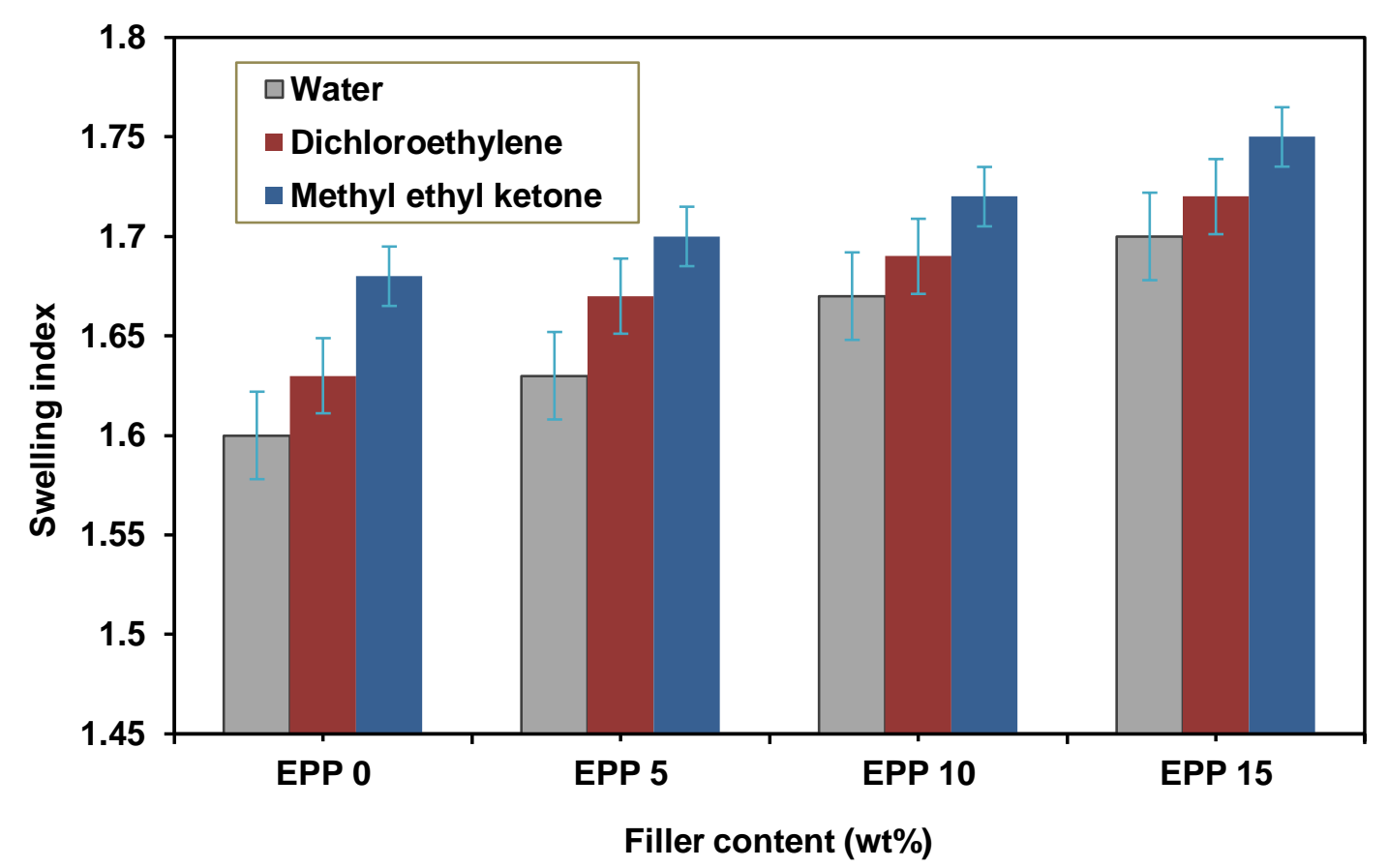

Fig. 16. Swelling properties of unfilled and PLSS dust-filled palm-epoxy composites

\section{CONCLUSIONS}

The static and dynamic mechanical properties of the palm/epoxy laminated composites used in combination with PLSS particles were investigated. Various properties of the hybrid composites including tensile modulus, flexural modulus, and impact strength were increased due to proper mechanical interlocking of the epoxy with the PLSS particles and palm fiber. Micrographs of the fractured tensile, flexural, and impact surfaces of the samples confirmed it. A significant improvement in storage modulus (2045 to $2962 \mathrm{MPa}$ ) was observed in the glassy region after incorporating filler into the palm-epoxy composite. A low $\tan \delta$ value was observed for the EPP0 (unfilled) composite, which indicates strong interfacial adhesion between the fiber and matrix. Filler addition increased the heterogeneity of the composite, as observed from the ColeCole plot. Further, PLSS addition increased both the swelling index and weight gain of the palm-epoxy composites. With the increment of PLSS particles in the epoxy resin, the viscosity of the matrix increased. Beyond $15 \mathrm{wt} \%$ of PLSS addition into the epoxy, it was difficult to fabricate the laminates using the hand-lay-up technique. Finally, the PLSS filled palm-epoxy composites could be used for structural applications in the automotive, aerospace, sports and many other industries.

\section{REFERENCES CITED}

Abdul Khalil, H. P. S., Jawaid, M., and Abu Bakar, A. (2011). "Woven hybrid composites: Water absorption and thickness swelling behaviors," BioResources 6(2), 
1043-1052. DOI: 10.15376/biores.6.2.1043-1052

Adak, N. C., Chhetri, S., Kim, N. H., Murmu, N. C., Samanta, P., and Kuila, T. (2018). "Static and dynamic mechanical properties of graphene oxide-incorporated woven carbon fiber/epoxy composite," J. Mat. Eng. Perform. 27(3), 1138-1147. DOI: $10.1007 / \mathrm{s} 11665-018-3201-5$

Akkus, M., Ozkan, N., and Bakir, U. (2018). "Efficient acetylation of xylans by exploiting the potassium acetate formed during the alkaline extraction," J. Polym. Environ. 26, 3397-3403. DOI: 10.1007/s10924-018-1221-8.

Araujo, R. S., Marques, M. P. V., Oliveria, P. F., and Rezende, C. C. (2018). "Biocomposites based on poly (lactic acid) containing mallow and eucalyptus surface modified natural fibers," J. Polym. Environ. 26(9), 3785-3791.DOI:10.1007/s10924018-1253-0

ASTM D256-08 (2008). "Standard test method for glass transition temperature (DMA $\mathrm{Tg}$ ) of polymer matrix composites by dynamic mechanical analysis (DMA)," ASTM International, West Conshohocken, PA, USA.

ASTM E1131-08 (2008). "Standard test method for compositional analysis by thermogravimetry," ASTM International, West Conshohocken, PA, USA.

ASTM B117-03 (2003). "Standard practice for operating salt spray (fog) apparatus, "ASTM International, West Conshohocken, PA, USA.

Asumani, O. M. L., Reid, R. G., and Paskaramoorthy, R. (2012). "The effects of alkalisilane treatment on the tensile and flexural properties of short fiber non-woven kenaf reinforced polypropylene composites," Compos. Part A-Eng. 43, 1431-1440.DOI: 10.1016/j.compositesa.2012.04.007

Atiqah, A., Jawaid, M., Sapuan, S. M., Ishak, M. R., and Alothman, O. Y. (2018). "Thermal properties of sugar palm/glass fiber reinforced thermoplastic polyurethane hybrid composites," Compos. Str. (In Press) DOI: 10.1016/j.compstruct.2018.05.009

Atiqah, A., Jawaid, M., Ishak, M. R., and Sapuan, S. M. (2017). "Effect of alkali and silane treatments on mechanical and interfacial bonding strength of sugar palm fibers with thermoplastic polyurethane," Journal of Natural Fiber 15, 251-261. DOI: $10.1080 / 15440478.2017 .1325427$

Biswas, S. (2014). "Erosion wear behavior of copper slag filled short bamboo fiber reinforced epoxy composites," International Journal of Engineering and Technology 6(2), 91-94. DOI:10.7763/IJET.2014.V6.672

Chee, S. S., Jawaid, M., Sultan, M. T. H., Alothman, O. Y., and Abdullah, L. C. (2019). "Thermomechanical and dynamic mechanical properties of bamboo/woven kenaf mat reinforced epoxy hybrid composites," Compos. Part-B Eng. 163, 165-174. DOI: 10.1016/j.compositesb.2018.11.039

Demir, H., Atikler, U., Balkose, D., and Tihminlioglu, F. (2006). "The effect of fiber surface treatments on the tensile and water sorption properties of polypropylene-luffa fiber composites," Compos. Part A-Apply. S. 37(3), 447-456. DOI:

10.1016/j.compositesa.2005.05.036

De Medeiros, E. S., Agnelli, J. A. M., Joseph, K., De Carvalho, L. H., and Mattoso, L. H. C. (2005). "Mechanical properties of phenolic composites reinforced with jute/cotton hybrid fabrics," Polym. Compos. 26, 1-11. DOI: 10.1002/pc.20063

Fiore, V., Bella, G. D., and Valenza, A. (2015). "The effect of alkaline treatment on mechanical properties of kenaf fibers and their epoxy composites," Compos. Part BEng. 68, 14-21. DOI: 10.1016/j.compositesb.2014.08.025 
Gupta, A., Kumar, A., Patnaik, A., and Biswas, S. (2012). "Effect of filler content and alkalization on mechanical and erosion wear behavior of CBPD filled bamboo fiber composites," Journal of Surface Engineered Materials and Advanced Technology 2(3), 149-157. DOI:10.4236/jsemat.2012.23024

Huang, Q., Zhao, J., Liu, M., Chen, J., Zhu, X., and Wu, T. (2018). "Preparation of polyethylene polyamine@ tannic acid encapsulated Mg Al-layered double hydroxide for the efficient removal of copper (II) ions from aqueous solution," J. Taiwan Inst. Chem. Eng. 82, 92-101. DOI: 10.1016/j.jtice.2017.10.019

Jabbar, A., Militky, J., Wiener, J., and Karahan, M. (2015). "Static and dynamic mechanical properties of novel treated jute/green epoxy composites," Text. Res. Journ. 86(9), 960-974. DOI: 10.1177/0040517515596936

Jawaid, M., Abdul Khalil, H. P. S., Hassan, A., Dungani, R., and Hadiyane, A. (2013). "Effect of jute fiber loading on tensile and dynamic mechanical properties of oil palm-epoxy composites," Compos. Part B-Eng. 45, 619-624. DOI: 10.1016/j.compositesb.2012.04.068

Jesuarockiam, N., Jawaid, M., Zainudin, E. S., Thariq Hameed Sultan, M., and Yahaya, R. (2019). "Enhanced thermal and dynamic mechanical properties of synthetic/natural hybrid composites with graphene nanoplatelets," Polymers 11(7), 1085. DOI: 10.3390/polym11071085

Ji, L. M., Li, L. J., Liu, Z. Q., Zhang, B., Nie, F., Zeng, Z. M., Song, F. G., Zhang, Y. H. and Jia, X. H. (2011). "Preparation and characterization of $\mathrm{Mg}(\mathrm{OH})_{2}$ flame-retardant with particular morphology via hydrothermal process," Adv. Mater. Res.1506-1507, 1311-1316. DOI: 10.4028/www.scientific.net/AMR.306-307.1311

Kar, J., Rout, A. K., and Sutar, A. K. (2018). "Physical, mechanical, and erosion characterization of palm leaf stalk fiber reinforced epoxy composites filled with palm leaf stem stalk (PLSS) powder," BioResources 13(4), 7212-7231.

DOI:10.15376/biores.13.4.7212-7231

Karaduman, Y. (2018). "Experimental investigation on flexural and dynamic mechanical properties of jute fiber/cork-reinforced polyester sandwich composites," BioResources 13(2), 3958-3970. DOI:10.15376/biores.13.2.3958-3970

Kumar, R. N., Hynes, R. J., Senthamaraikannan, P., Saravanakumar, S., and Sanjay, M. R. (2018). "Physicochemical and thermal properties of Ceiba pentandra bark fiber," Journal of Natural Fibers 15(6), 822-829. DOI: 10.1080/ 15440478.2017.1369208

Law, T. T., and Ishak Mohd, Z. A. (2010). "Water absorption and dimensional stability of short kenaf fiber-filled polypropylene composites treated with maleated polypropylene," J. Appl. Polym. Sci. 120, 563-572. DOI: 10.1002/app.33184

Liu, Y., Ma, Y., Yu, J., Zhuang, J., Wu, S., and Tong, J. (2019). “Development and characterization of alkali-treated abaca fiber reinforced friction composites," Composite Interfaces 26 (1), 67-82. DOI:10.1080/09276440.2018.1472456

Lomelí-Ramírez, M. G., Kestur, S. G., Manríquez-González, R., Iwakiri, S., de Muniz, G. B., and Flores-Sahagun, T. S. (2014). "Bio-composites of cassava starch-green coconut fiber: Part II-Structure and properties," Carbohydr. Polym. 102, 576-583. DOI: 10.1016/j.carbpol.2013.11.020

Manimaran, P., Prithiviraj, M., Saravanakumar, S. S., Arthanarieswaran, V. P., and Senthamaraikannan, P. (2018). "Physicochemical, tensile, and thermal characterization of new natural cellulosic fibers from the stems of Sida cordifolia," Journal of Natural Fibers 15(6), 860-869. DOI:10.1080/15440478.2017.1376301 
Md Shah, A. U., Sultan, M. T. H., Cardona, F., Jawaid, M., Talib, A. R. A., and Yidris, N. (2017). "Thermal analysis of bamboo fiber and its composites," BioResources 12(2), 2394-2406. DOI:10.15376/biores.12.2.2394-2406

Md Shah, A. U., Sultan, M. T., and Jawaid, M. (2019). "Sandwich-structured bamboo powder/glass-fiber-reinforced epoxy hybrid composites-Mechanical performance in static and dynamic evaluations," J. Sandw. Struct. Mater. 1-18. DOI: $10.1177 / 1099636218822740$

Mohan, R., Shridhar, M. K., and Rao, R. M. V. G. K. (1983). "Compressive strength of jute-glass hybrid fiber composites," J. Mat. Sci. 2(3), 99-102. DOI: 10.1007/BF00722222

Martinez-Hernandez, A. L., Velasco-Santos, De Icaza, M., and Victor, M. C. (2007). "Dynamic mechanical and thermal analysis of polymeric composites reinforced with keratin fibers from chicken feathers," Compos. Part B-Eng. 38, 405-410. DOI: 10.1016/j.compositesb.2006.06.013

Nair, K. M., Thomas, S., and Groeninckx, G. (2001). "Thermal and dynamic mechanical analysis of polystyrene composites reinforced with short sisal fibers," Compos. Sci. Technol. 61(16), 2519-2529. DOI: 10.1016/S0266-3538(01)00170-1

Nayak, S. K., and Mohanty, S. (2010). "Sisal glass fiber reinforced PP hybrid composites: Effect of MAPP on the dynamic mechanical and thermal properties," $J$. Ref. Plast. Compos. 29, 1551-1568. DOI: 10.1177/0731684409337632

Nunna, S., Chandra, P. R., Shrivastava, S., and Jalan, A. K. (2012). "A review on the mechanical behavior of natural fiber-based hybrid composites," J. Reinf. Plast. Compos. 31(11), 759-769. DOI: 10.1177/0731684412444325

Netravali, A. N. (2007). “Advanced green composites," Adv. Compos. Mater. 16(4), 269282. DOI: $10.1163 / 156855107782325230$

Obi Reddy, K., Uma Maheswari, C., Shukla, M., Song, J. I., and Varada Rajulu, A. (2013). "Tensile and structural characterization of alkali-treated Borassus fruit fine fibers," Compos. Part B-Eng. 44(1), 433-438. DOI:10.1016/j.compositesb.2012.04.075

Ojha, A. R., and Biswal, S. K. (2019). “Thermo physicomechanical behavior of palm stalk fiber reinforced epoxy composites filled with granite powder," Composite Communication 16, 158-161. DOI: 10.1016/j.coco.2019.10.003

Patnaik, T. P., and Nayak, S. S. (2016). "Investigation on physicomechanical and thermo-mechanical analysis of alumina filled needle-punch nonwoven jute epoxy composites," Polym. Composite, 39, 1553-1561. DOI: 10.1002/pc.24099

Pawar, M. J., Patnaik, A., and Nagar, R. (2015). "Investigation on mechanical and thermo-mechanical properties of granite powder reinforced epoxy composites," Polym. Composite 38(4), 736-748. DOI: 10.1002/pc.23633

Prasob, A., and Sasikumar, M. (2018). "Static and dynamic behavior of jute/epoxy composites with $\mathrm{ZnO}$ and $\mathrm{TiO}_{2}$ fillers at different temperature conditions," Polym. Testing 69, 52-62. DOI: 10.1016/j.polymertesting.2018.04.040

Ray, D., Sarkar, B. K., Das, S., and Rana, A. K. (2002). "Dynamic mechanical and thermal analysis of vinyl ester-resin-matrix composites reinforced with untreated and alkali-treated jute fibers," Compos. Sci. Technol. 62, 911-917. DOI: 10.1016/S02663538(02)00005-2

Reddy, J. P., and Rahim, J. W. (2018). "Extraction and characterization of cellulose microfibers from agricultural wastes of onion and garlic," Journal of Natural Fibers 
15 (4), 465-473. DOI: 10.1080/15440478.2014.945227

Reddy, R. M., Krishnudu, D. M., Reddy, B. M., and Reddy, P. V. (2019). "Effect of alkali treatment on mechanical properties of tapsi fiber reinforced polyester composites," Emerging Trends in Mechanical Eng. 85-91. DOI: 10.1007/978-98132-9931-3_9

Rout, A. K., Kar, J., and Jesthi, D. K. (2016). "Effect of surface treatment on the physical, chemical, and mechanical properties of palm tree leaf stalk fibers," BioResources 11(2), 4432-4445. DOI:10.15376/biores.11.2.4432-4445

Rout, J., Mishra, M., Tripathy, S. S., Nayak, S. K., and Mohanty, A. K. (2001). "The influence of fiber treatment on the performance of coir-polyester composites," Compos. Sci. Technol. 61(9), 1303-1310.DOI: 10.1016/S0266-3538(01)00021-5

Rout, A. K., and Satapathy, A. (2012). "Study on mechanical and tribo-performance of rice-husk filled glass-epoxy hybrid composites," Mat. Des. 41, 131-141.DOI: 10.1016/j.matdes.2012.05.002

Samal, S. K., Mohanty, S., and Nayak, S. K. (2009). "Polypropylene-bamboo/glass fiber hybrid composites: Fabrication and analysis of mechanical, morphological, thermal, and dynamic mechanical behavior," J. Reinf. Plast. Compos. 28, 2729-2747. DOI: $10.1177 / 0731684408093451$

Saba, N., Jawaid, M., Alothman, O. Y., and Paridah, M. T. (2016). "A review on dynamic mechanical properties of natural fibre reinforced polymer composites," Constr. Build. Mater. 106, 149-159. DOI: 10.1016/j.conbuildmat.2015.12.075

Saba, N., Alothman, O. Y., Almutairi, Z., and Jawaid, M. (2019). "Magnesium hydroxide reinforced kenaf fibers/epoxy hybrid composites: Mechanical and thermo-mechanical properties," Const. Build. Mat. 201, 138-148. DOI:

10.1016/j.conbuildmat.2018.12.182

Sanjay, M. R., and Yogesha, B. (2017). "Studies on natural/glass fiber reinforced polymer hybrid composites: An evolution," Materials. Today: Proceed. 4, 27392747. DOI: 10.1016/j.matpr.2017.02.151

Sarkar, N., Sahoo, G., Khuntia, T., Priyadarsini, P., Mohanty, J. R., and Swain, S. K. (2017). "Fabrication of acrylic modified coconut fiber reinforced polypropylene biocomposites: Astudy of mechanical, thermal, and erosion properties," Polym. Compos. 38(12), 2852-2862. DOI: $10.1002 / p c .23887$

Satapathy, S., and Kothapalli, R. V. S. (2017). "Mechanical dynamic mechanical and thermal properties of banana fiber/recycled high-density polyethylene biocomposite filled with fly ash cenospheres," J. Polym. Environ. 26(1), 200-213. DOI: 10.1007/s 10924-017-0938-0

Senturk, O., Senturk, A. E., and Palabiyik, M. (2018). "Evaluation of the hybrid effect on the thermomechanical and mechanical properties of calcite/SGF/PP composites," Compos. Part B-Eng. 140, 68-77. DOI: 10.1016/j.compositesb.2017.12.021

Srivastava, V. K., and Pawar, A. G. (2006). "Solid particle erosion of glass fibre reinforced fly ash filled epoxy resin composites," Compos. Sci. Technol. 66(15), 3021-3028. DOI:10.1016/j.compscitech.2006.02.004

Umashankaran, M., and Gopalakrishnan, S. (2020). "Effect of sodium hydroxide treatment on physico-chemical, thermal, tensile and surface morphological properties of Pongamia pinnata L. bark fiber," Journal of Natural Fibers 2020, 1-14. DOI: 10.1080/15440478.2019.1711287

Zafar, M. T., Maiti, S. N., and Ghosh, A. K. (2016). "Effects of surface treatments of jute 
fibers on the microstructural and mechanical responses of poly(lactic acid)/jute fiber biocomposites," RSC Adv. 6, 73373-73382. DOI: 10.1039/C6RA17894D

Zuhudi, N. Z. M., Lin, R. J., and Jayaraman, K. (2016). "Flammability, thermal and dynamic mechanical properties of bamboo-glass hybrid composites," $J$.

Thermoplastic. Compos. Mater. 29, 1210-1228. DOI: 10.1177/0892705714563118

Article submitted: November 9, 2019; Peer review completed: December 15, 2019;

Revised version received and accepted: April 10, 2020; Published: April 20, 2020.

DOI: $10.15376 /$ biores. 15.2.4249-4270 